\title{
Knowledge and Understanding of Endodontic Concepts, Working Width vs Working Length and Variable Taper vs Constant Taper among Endodontic Practitioners
}

\author{
Loai Alsofi
}

\begin{abstract}
Aim: The present study aims to assess the knowledge of some endodontic concepts, working width (WW) vs working length (WL) and variable taper vs constant taper among endodontic practitioners.

Materials and methods: A descriptive study design was employed to assess the knowledge and understanding of endodontics practitioners. The questionnaire was distributed among 400 participants, which was composed of different items and was measured using different rating scales. Results: Descriptive statistics were presented in tables based on the frequency and percentages of responses from participants. Out of 400 participants, 363 responses were obtained. The results showed that the radiographic method and the electronic method were both useful for determining the WL during root canal treatment. Moreover, a majority of the participants preferred to use WL with $0.5 \mathrm{~mm}$ shorter than apex, while a few of them preferred $1 \mathrm{~mm}$ shorter than the apex. The significant factors that help in determining the WW and length included canal taper, canal morphology, and canal curvature.

Conclusion: The study results have concluded that both the radiographic method and the electronic method are useful in determining the WL. Canal geometry and morphology were among the factors that influence the WL detection method.

Keywords: Constant taper, Endodontic concepts, Variable taper, Working length, Working width.

World Journal of Dentistry (2019): 10.5005/jp-journals-10015-1635
\end{abstract}

\section{INTRODUCTION}

One of the major components of root canal treatment is canal preparation. It is directly related to subsequent disinfection and obturation of the root canal. To allow effective chemo-mechanical preparation and obturation of the root canal, instrumentation must result in a continuously tapered shape with the smallest diameter at the apical foramen and the largest at the orifice. ${ }^{1}$ Despite the manufacturing of so many rotary $\mathrm{Ni}-\mathrm{Ti}$ instruments, only a few matched the level of these primary objectives of root canal preparation consistently. ${ }^{2}$ Root canal shaping is one of the most important steps for successful root canal therapy. Therefore, understanding the complexity of the root canal system has led to the development of newer techniques, instruments, and materials. It is important to accurately understand concepts such as endodontic WL and WW of each canal. Failure to accurately determine the WL may result in apical perforation and subsequent extrusion of irrigation solutions and obturation material into the periapical tissues. ${ }^{3-6}$ It was found out that the palatal and the mesiobuccal roots of maxillary molars present inaccurate radiographic WL readings. ${ }^{7}$

Root canal preparation with rotary nickel-titanium ( $\mathrm{Ni}-\mathrm{Ti}$ ) instruments became popular in the last decade as it facilitates the difficult and time-consuming process of shaping and improves the final quality of root canal preparation. Even in severely curved canals, as demonstrated, $\mathrm{Ni}-\mathrm{Ti}$ instruments are able to maintain canal shape. ${ }^{8,9}$ After getting these positive results, new $\mathrm{Ni}-\mathrm{Ti}$ systems are being introduced with new blade designs and tapers, claiming increased safety and easiness to use. Currently, available $\mathrm{Ni}-\mathrm{Ti}$ instruments vary in their designs. Various blade designs, different tapers, additional grooves, and different tip geometries
Department of Endodontics, Faculty of Dentistry, King Abdulaziz University, Jeddah, Kingdom of Saudi Arabia

Corresponding Author: Loai Alsofi, Department of Endodontics, Faculty of Dentistry, King Abdulaziz University, Jeddah, Kingdom of Saudi Arabia, Phone: +966 555318481, e-mail: lalsofi@kau.edu.sa

How to cite this article: Alsofi L. Knowledge and Understanding of Endodontic Concepts, Working Width vs Working Length and Variable Taper vs Constant Taper among Endodontic Practitioners. World J Dent 2019;10(3):219-226.

Source of support: Nil

Conflict of interest: None

have been suggested. According to the taper, the shaft design can be categorized into two categories: progressive taper and constant taper. Instruments with progressive taper can shape canals more quickly than instruments with constant taper. ${ }^{10}$ It is claimed that instruments with a progressive taper that increases coronally have enhanced flexibility at the apical and middle parts of the instrument.

Dentists who have incorporated rotary instrumentation into their routine practice seek a simple system of files and look for an easier technique to be used in daily operations. Many dentists are attracted by the techniques which involve only a few instruments. With their initial choices, some of them rapidly find a practical comfort level. They add their own modifications per acquired experience, propound to use other instruments and techniques. The new design and usage of this modality for canal preparation required close understanding toward the physics of rotary instrumentation. 
The present study aims to assess the knowledge of some endodontic concepts, WW vs WL and variable taper vs constant taper among endodontic practitioners.

\section{Materials and Methods}

This study was based on a descriptive design to assess the knowledge and understanding of endodontics practitioners. The study was conducted at the Faculty of Dentistry, King Abdulaziz University, Jeddah, Kingdom of Saudi Arabia. An informed consent form has been signed by all the participants based on their willingness by ensuring their confidentiality and anonymity throughout the study period.

The study data were collected using a primary data collection approach (survey questionnaire), which included WW, WL, variable taper, and constant taper. The questionnaire was based on two sections: demographics and questions comprising a total of 21 questions. The questionnaire has been distributed to the potential participants through an online survey. A total of 400 dental practitioners from different dental sectors in Saudi Arabia were approached, out of which only 363 answered the questionnaire completely. The variables listed in the questionnaire were composed of different items and were measured using different rating scales.

Descriptive statistics were used to present the frequencies and percentages of the demographic variables, while cross-tabulation was performed to show the knowledge and understanding of endodontic concepts among practitioners.

\section{Results}

A total of 400 participants were approached initially from which only 363 participants had completely returned the questionnaire and, therefore, were considered as the final sample for the study.

Table 1 presents the descriptive statistics based on the demographic's variables, including gender, age, years in practice, and academic degrees. Gender distribution of the participants was of the following: $70 \%$ of females and $30 \%$ of males. Most of the participants had experience of less than 1 year (51.51\%), followed by $2-5$ years (31.6\%), and more than 10 years (9.09\%). Most of the participants possess a bachelor's degree (87.05\%).

\section{WL AND WW}

This section presents the definition, determination, significance, measurement, and factors affecting WL and WW. Table 2 shows the definition and determination of WL and reveals the definition of WL as "The distance between the reference point coronally and the anatomical apex" (37.19\%). Most of the participants stated that both the radiographic method and the electronic method are used to determine the WL (78.23\%).

Table 3 presents the significance of WL by listing the most important factors. These factors include "Determine the instrument length in the canal" (14.6\%), "Limits the depth to which the canal filling may be placed" (11.29\%), and "Determination of the success of treatment" (3.3\%). Most of the participants stated that " $0.5 \mathrm{~mm}$ shorter than the apex" is the accurate measurement of WL. However, a few of the participants preferred to use WL with $1 \mathrm{~mm}$ shorter than the apex (Table 4).

The determination of WL and WW is affected by several factors (Table 5). In this regard, canal morphology, canal taper, and canal curvature were the most important factors to determine the WW and the WW (57\%).
Table 1: Demographic distribution of the participants

\begin{tabular}{lrc}
\hline & \multicolumn{2}{c}{ Descriptive statistics } \\
\cline { 2 - 3 } Variables & $n$ & $\%$ \\
\hline Gender & 109 & 30 \\
Male & 254 & 70 \\
Female & & \\
Age & 282 & 77.7 \\
21-30 & 55 & 15.15 \\
31-40 & 24 & 6.61 \\
41-50 & 2 & 0.55 \\
51-60 & & \\
Years in practice & 187 & 51.51 \\
Less than 1 year & 115 & 31.6 \\
2-5 years & 28 & 7.71 \\
6-10 years & 33 & 9.09 \\
More than 10 years & & \\
Academic degrees & 316 & 87.05 \\
Bachelors & 12 & 3.3 \\
Masters & 4 & 1.1 \\
PhD & 3 & 0.8 \\
Doctorate & 6 & 1.65 \\
International board certificate & 20 & 5.50 \\
Saudi board certificate & & 0.55 \\
Diploma & & \\
\hline
\end{tabular}

Table 2: Frequency and percentage of reponses to the definition and the method of determination of WL

\begin{tabular}{lrc}
\hline & $n$ & $\%$ \\
\hline $\begin{array}{l}\text { Definition of working length } \\
\quad \text { The distance between the reference point }\end{array}$ & 135 & 37.19 \\
$\begin{array}{l}\text { coronally and the anatomical apex } \\
\text { The distance between the reference point }\end{array}$ & 126 & 34.71 \\
$\quad \begin{array}{l}\text { coronally and the radiographic apex } \\
\text { Both are true }\end{array}$ & 95 & 26.17 \\
$\quad$ None of the above are true & 6 & 1.65 \\
I do not know the right answer & 1 & 0.2 \\
Determination of working length & & \\
$\quad$ Radiographic method & 17 & 4.68 \\
Electronic apex locator & 61 & 16.8 \\
Both & 284 & 78.23 \\
I do not know the right answer & 1 & 0.2 \\
\hline
\end{tabular}

Table 3: Factors that test significance of WL

\begin{tabular}{lrl}
\hline Significance of working length & $n$ & $\%$ \\
\hline Determine the instrument length in the canal & 53 & 14.6 \\
Limits the depth to which the canal filling & 41 & 11.29 \\
may be placed & & \\
Limits the postoperative pain and discomfort & 4 & 1.1 \\
Determination of the success of treatment & 12 & 3.3 \\
All of the above & 243 & 67 \\
I do not know the right answer & 10 & 2.75 \\
\hline
\end{tabular}


Table 4: A question to verify the preferred WL extension among participants

\begin{tabular}{lll}
\hline $\begin{array}{l}\text { Measurement of working } \\
\text { length }\end{array}$ & $n$ & $\%$ \\
\hline $0.5 \mathrm{~mm}$ shorter than the apex & 200 & 55 \\
1 mm shorter than the apex & 88 & 25 \\
None of the above & 75 & 20.66 \\
\hline
\end{tabular}

Table 5: Factors that affect the determination of WW and WL

\begin{tabular}{lcr}
\hline Factors & $n$ & $\%$ \\
\hline Canal morphology & 52 & 8.25 \\
Canal taper & 33 & 9 \\
Canal curvature & 16 & 4 \\
All of the above & 207 & 57 \\
I do not know the right answer & 55 & 15 \\
\hline
\end{tabular}

\section{Variable and Constant Taper}

This section presents the knowledge and understanding of variable and constant tapers in the form of meaning, and types of files according to the taper. Table 6 presents the meaning of variable and constant taper. Most of the participants understand variable taper as "a series of rotary files that have the same common apical tip size but vary in their tapers" (29.7\%), whereas participants reveal the meaning of constant taper as "a series of files with a constant taper with varying apical tip sizes" (46.8\%).

Table 7 presents the features of variable and constant taper files and shows the following result: "conservative in the coronal third of the radicular dentin" as the most important feature of the variable taper (23.96\%) and constant taper, respectively (33.3\%).

Table 8 presents the different types of files, weather variable taper, or constant taper. The findings showed the preference of protaper next as the most important type of variable taper file (66.39\%), whereas K-Flexofiles were the most important type of the constant taper file (74.38\%).

\section{Preparations Using Variable and Constant Taper}

This section shows the effectiveness of variable and constant tapers in canal preparation (Table 9). The findings showed that variable

Table 6: Definitions of variable and constant taper

\begin{tabular}{|c|c|c|}
\hline & $n$ & $\%$ \\
\hline \multicolumn{3}{|l|}{ Meaning of variable taper } \\
\hline $\begin{array}{l}\text { A series of rotary files that have the same } \\
\text { common apical tip size but vary in their tapers }\end{array}$ & 108 & 29.7 \\
\hline $\begin{array}{l}\text { A series of files with a constant taper and with } \\
\text { varying apical tip sizes }\end{array}$ & 97 & 26.7 \\
\hline Using single NI TI file with variable taper & 54 & 14.8 \\
\hline I do not know the right answer & 104 & 28.65 \\
\hline \multicolumn{3}{|l|}{ Meaning of variable taper } \\
\hline $\begin{array}{l}\text { A series of rotary files that have the same com- } \\
\text { mon apical tip size but vary in their tapers }\end{array}$ & 95 & 26 \\
\hline $\begin{array}{l}\text { A series of files with a constant taper and with } \\
\text { varying apical tip sizes }\end{array}$ & 170 & 46.8 \\
\hline Using single Ni Ti file with constant taper & 98 & 27 \\
\hline
\end{tabular}

Table 7: Features of variable and constant taper

\begin{tabular}{|c|c|c|}
\hline & $n$ & $\%$ \\
\hline \multicolumn{3}{|l|}{ Features of variable taper } \\
\hline Decrease the possibility of fracture & 41 & 11 \\
\hline $\begin{array}{l}\text { Conservative in the coronal third of the root } \\
\text { canal }\end{array}$ & 87 & 23.96 \\
\hline Facilitates the cone fit & 35 & 9 \\
\hline $\begin{array}{l}\text { Faster preparation of the coronal third of the } \\
\text { canal }\end{array}$ & 65 & 17.9 \\
\hline I do not know the right answer & 135 & 37.19 \\
\hline \multicolumn{3}{|l|}{ Features of constant taper } \\
\hline Decrease the possibility of fracture & 44 & 12 \\
\hline $\begin{array}{l}\text { Conservative in the coronal third of the root } \\
\text { canal }\end{array}$ & 121 & 33.3 \\
\hline Associated with thermoplastic obturation & 20 & 5.5 \\
\hline $\begin{array}{l}\text { Faster preparation of the coronal third of the } \\
\text { canal }\end{array}$ & 53 & 14.6 \\
\hline I do not know the right answer & 125 & 34.4 \\
\hline
\end{tabular}

Table 8: A question to test the knowledge of taper characteristics of different rotary files

\begin{tabular}{lrl}
\hline & $n$ & $\%$ \\
\hline Variable taper & & \\
$\quad$ Protaper next & 241 & 66.39 \\
Protaper universal & 85 & 23.4 \\
Protaper gold & 37 & 10 \\
Constant taper & & \\
Revo-S & 74 & 20.3 \\
K-Flexofiles & 270 & 74.38 \\
I-Race & 19 & 5.2 \\
\hline
\end{tabular}

Table 9: A question to test preparations features of variable taper and constant taper rotary files

\begin{tabular}{lclcc}
\hline & $\begin{array}{l}\text { Variable } \\
\text { taper }\end{array}$ & $\begin{array}{l}\text { Constant } \\
\text { taper }\end{array}$ & $\begin{array}{l}\text { All of the } \\
\text { above }\end{array}$ & $\begin{array}{l}\text { Ido not } \\
\text { know the } \\
\text { right answer }\end{array}$ \\
\hline $\begin{array}{l}\text { High efficiency } \\
\text { of cleaning and } \\
\text { debridement }\end{array}$ & 91 & 56 & 122 & 94 \\
$\begin{array}{l}\text { Resistance and } \\
\text { retention form }\end{array}$ & 106 & 62 & 94 & 101 \\
\begin{tabular}{l} 
Better prognosis \\
\hline
\end{tabular} & 144 & 65 & 154 & - \\
\hline
\end{tabular}

taper is used for better prognosis $(n=144)$, whereas constant taper is used for maintaining resistance and retention form $(n=62)$.

\section{Discussion}

The results of the present study showed that the radiographic method and the electronic method were useful in determining the WL as narrated by the majority of the participants. The success of root canal treatment depends on the apical termination of obturation, for which, the WL is an important element. A study conducted by Rambabu et al. evaluated the preoperative WL in radiograph and grid radiograph. ${ }^{11}$ This approach was concerned with the electronic apex locator within the single-rooted teeth. As compared with the conventional WL and apex locator WL, grid WL and apex locator WL showed a high correlation. Therefore, 
radiographic grid along with the apex locator is considered as an effective measuring tool for a single-rooted tooth.

Another similar study conducted by Carneiro et al. focused on the accuracy of electronic apex locator for determining the real WL in comparison to the radiographic method. ${ }^{12}$ The study results showed that there was a no significant difference between the electronic and radiographic methods. Therefore, it can be concluded that the WL of root canals can be easily determined through electronic apex locator as it is a reliable and accurate method, which optimizes the endodontic procedure in clinical practice. According to the results of the present study, a majority of the study participants reported that the accurate measurement of WL is $0.5 \mathrm{~mm}$ shorter than the radiographic apex. At present, apex locators are extensively used in the endodontic therapy and these devices have become indispensable in the clinical practice.

The field of endodontics has gained attention to a new level with the advent of new inventions that enter this field each day. This has resulted in the shift in direction for a root canal from biomechanical preparation to chemo-biomechanical preparation. The access of endodontic irrigants to the WL during treatment is significant, although root canal treatment should not only depend on proper cleaning and shaping procedures. ${ }^{13}$ The endodontic treatment provides predictable clinical results when instrumentation and obturation reach the apical foramen. The results of the present study have demonstrated that there were some participants who were in favor of using WL that is $1 \mathrm{~mm}$ shorter than the apex. It was shown that working at $1 \mathrm{~mm}$ shorter than the apex resulted in the reduction of cracks in the apical region. ${ }^{14}$

Using radiographs alone to determine the WL presents some difficulty when the needed adjustment is more than $1 \mathrm{~mm} .^{15}$ Different radiographic conditions affect the accuracy of WL determination. ${ }^{16} \mathrm{~A}$ study conducted by Gutmann showed that establishment of WL close to the canal exit or slightly short to the apical foramen is required for cleaning the entire length of the canal. ${ }^{17}$ The same study has also revealed that the files placed to the apical extent of the root will likely be outside the confines of the canal, because the root apex may present with several morphological variations in the presence of apical resorption. ${ }^{17}$ A ledge is likely to be created through modification of instrumentation that is associated with re-determination of WL. ${ }^{18}$ The use of the Root ZX apex locator combined with radiographs is recommended for WL determination. ${ }^{19}$ In another study, it was found out that that the location of the apical foramen can be determined using radiographs. ${ }^{20}$

The present study aimed to understand some endodontic concepts, WW vs WL and variable taper vs constant taper among participants. The factors that help in determining the WW and WL include canal taper, canal morphology, and canal curvature. The study results have preferred protaper next as the most important type of variable taper file, whereas K-Flexofiles were the most important type of the constant taper file.

\section{Conclusion}

The study results have concluded that variable and constant tapers both play an effective role in canal preparation. It also showed that both the radiographic method and the electronic method are both useful in the determination of WL. One limitation of the study was that it did not assess factors that may increase the difficulty of root canal preparation or instrumentation.

\section{Clinical Significance}

The study tests the importance of the understanding of endodontic concepts in the success of root canal treatment.

\section{ACKnOWLedgments}

The author is very thankful to all the associated personnel in any reference that contributed in/for the purpose of this research.

\section{References}

1. Michael HU, Lsmann O. Mechanical preparation of root canals: shaping goals, techniques and means. Endodontic Topics 2005;10: 30-76. DOI: 10.1111/j.1601-1546.2005.00152.x.

2. Schafer $E$, Erler $M$, et al. Comparative study on the shaping ability and cleaning efficiency of rotary Mtwo instruments. Part 1. Shaping ability in simulated curved canals. Int Endod J 2006;39(3):196-202. DOI: 10.1111/j.1365-2591.2006.01074.x.

3. Seltzer S, Bender IB, et al. Endodontic failures-an analysis based on clinical, roentgenographic, and histologic findings. I. Oral Surg Oral Med Oral Pathol 1967;23(4):500-516.

4. Swartz $D B$, Skidmore $A E$, et al. Twenty years of endodontic success and failure. J Endod 1983;9(5):198-202. DOI: 10.1016/S00992399(83)80092-2.

5. Sjogren $U$, Hagglund $B$, et al. Factors affecting the long-term results of endodontic treatment. J Endod 1990;16(10):498-504. DOI: 10.1016/ S0099-2399(07)80180-4.

6. Smith CS, Setchell DJ, et al. Factors influencing the success of conventional root canal therapy-a five-year retrospective study. Int Endod J 1993;26(6):321-333. DOI: 10.1111/j.1365-2591.1993.tb00765.x.

7. ElAyouti $A$, Weiger $R$, et al. Frequency of overinstrumentation with an acceptable radiographic working length. J Endod 2001;27(1):49-52.

8. Sel D. Efficiency of rotary nickel-titanium FlexMaster instruments compared with stainless steel hand K-Flexofile-Part 1. Shaping ability in simulated curved canals. Int Endod J 2002;35(6):13.

9. Yang GB, Zhou XD, et al. Shaping ability of progressive vs constant taper instruments in curved root canals of extracted teeth. Int Endod J 2007;40(9):707-714. DOI: 10.1111/j.1365-2591.2007.01296.x.

10. Veltri M, Mollo A, et al. A comparative study of Endoflare-Hero Shaper and Mtwo NiTi instruments in the preparation of curved root canals. Int Endod J 2005;38(9):610-616. DOI: 10.1111/j.13652591.2005.00989.x.

11. Rambabu T, Srikanth V, et al. Comparison of Tentative Radiographic Working Length with and without grid vs Electronic Apex Locator. Contemp Clin Dent 2018;9(1):88-91. DOI: 10.4103/ccd.ccd_790_17.

12. Carneiro JA, de Carvalho FMA, et al. Comparison of working length determination using apex locator and manual method-ex vivo study. Dentistry and Medical Research 2016;4(2):39-43. DOI: 10.4103/ 2348-1471.184730.

13. Sharma A, Kurtzman GM, et al. Accuracy comparison of three different electronic apex locators in single-rooted teeth-an in vitro study. Endodontic practice 2018;11(1):3. DOI: 10.1111/j.17474477.2006.00020.x.

14. Adorno CG, Yoshioka T, et al. The effect of working length and root canal preparation technique on crack development in the apical root canal wall. Int Endod J 2010;43(4):321-327. DOI: 10.1111/j.13652591.2010.01684.x.

15. Cox VS, Brown Jr CE, et al. Radiographic interpretation of endodontic file length. Oral Surg Oral Med Oral Pathol 1991;72(3):340-344. DOI: 10.1016/0030-4220(91)90230-A.

16. Orafi I, Worthington HV, et al. The impact of different viewing conditions on radiological file and working length measurement. Int Endod J 2010;43(7):600-607. DOI: 10.1111/j.1365-2591.2010.01744.x.

17. Gutmann JL. Apical termination of root canal procedures-ambiguity or disambiguation? Evidence-Based Endodontics 2016;1(1):4. DOI: 10.1186/s41121-016-0004-8 
18. Sinai I, Seltzer S, et al. Biologic aspects of endodontics. II. Periapical tissue reactions to pulp extirpation. Oral Surg Oral Med Oral Pathol 1967;23(5):664-679.

19. Kim $E$, Marmo $M$, et al. An in vivo comparison of working length determination by only root-ZX apex locator vs combining root-ZX apex locator with radiographs using a new impression technique. Oral
Surg Oral Med Oral Pathol Oral Radiol Endod 2008;105(4):e79-e83. DOI: 10.1016/j.tripleo.2007.12.009.

20. Olson AK, Goerig AC, et al. The ability of the radiograph to determine the location of the apical foramen. Int Endod J 1991;24(1):28-35. DOI: 10.1111/j.1365-2591.1991.tb00867.x. 


\section{Questionnaire}

What is
- $21-30$
- $31-40$
- $41-50$
- $51-60$
- $61-70$
- $71-80$

What is your gender?

- Male

- Female

What is your specialty?

- Student

- General Dentist

- Endodontist

- Oral surgery

- Periodontist

- Prosthodontist

- Orthodontist

- Saudi board resident, specify

- Other

Years in practice

- Less than one year

- 2-5 years

- 6-10 years

- More than 10 years

What is your highest academic degree?

- Bachelor

- Master

- Ph.D

- Doctorate

- International board certificate

- Saudi board certificate

- Diploma

Working length is defined as

- The distance between the reference point coronally and the anatomical apex

- The distance between the reference point coronally and the radiographic apex

- Both are true

- None of the above are true

- I do not know the right answer

The working length is determined by

- Radiographic method

- Electronic apex locator

- Both

- I do not know the right answer

Significance of working length determination is/are to

- Determine the instrument length in the canal

- Limits the depth to which the canal filling may be placed

- Limits the postoperative pain and discomfort

- Determination of the success of treatment

- All of the above

- I do not know the right answer 
Working width is defined as

- The largest diameter of the original canal size in the apical third

- The horizontal dimension of a root canal

- Both are true

- I do not know the right answer

Working length should be

- $0.5 \mathrm{~mm}$ shorter than the apex

- $1 \mathrm{~mm}$ shorter than the apex

- $2 \mathrm{~mm}$ shorter than the apex

- None of the above

Which factor/s affect the determination of working width and working length

- Canal morphology

- Canal taper

- Canal curvature

- All of the above

- I do not know the right answer

Root canal morphology is a critically important part for both conventional and surgical root canal therapy (RTC)

- True

- False

What is the meaning of the variable taper concept?

- A series of rotary files that have the same common apical tip size but vary in their tapers

- A series of files with a constant taper such and with varying apical tip sizes

- Using single NITI file with variable taper

- I do not know the right answer

What is the characteristic feature of variable taper?

- Promote disengagement of the instruments

- Conservative in the coronal third of the radicular dentin

- Facilitates the primary cone fit

- Preparation of the coronal third of the canal and for eliminating interferences.

- I do not know the right answer

Which type of variable taper files do you use?

- Protaper next

- Protaper Universal

- Protaper Gold

What is the meaning of the constant taper concept?

- A series of rotary files that have the same common apical tip size but vary in their tapers

- A series of files with a constant taper such and with varying apical tip sizes

- Using single NiTi file with constant taper

What is the characteristic feature of constant taper files?

- Promote disengagement of the instruments

- Conservative in the coronal third of the radicular dentin

- Associated with thermoplastic obturation

- Preparation of the coronal third of the canal and for eliminating interferences

- I do not know the right answer

Which type of constant taper files do you use?

- Revo-S

- K-Flexofiles

- I-Race.

Which of these preparations has high efficiency of cleaning and debridement?

- Variable taper prep

- Constant taper prep

- All of the above

- I do not know the right answer 
Which preparation achieves and keeps the resistance and retention form accurately?

- Variable taper prep

- Constant taper prep

- All of the above

- I do not know the right answer

In your opinion, which preparation gives better prognosis?

- Variable taper prep

- Constant taper prep

- All of the above 